\title{
A Comparison of the Effects of Grayanotoxin- Containing Honey (Mad Honey), Normal Honey, and Propolis on Fracture Healing
}

\author{
Aynur Sahin $^{a} \quad$ Suha Turkmen $^{\mathrm{b}} \quad$ Nizamettin Guzelc Ahmet Mentese $^{\mathrm{d}}$ \\ Suleyman Turedi ${ }^{a}$ Suleyman Caner Karahan ${ }^{d}$ Esin Yulug ${ }^{e}$ Selim Demir ${ }^{f}$ \\ Osman Aynacic Orhan Deger ${ }^{d}$ Abdulkadir Gunduz ${ }^{a}$ \\ a Department of Emergency Medicine, Faculty of Medicine, Karadeniz Technical University, Trabzon, Turkey; \\ ${ }^{b}$ Department of Emergency Medicine, Faculty of Medicine, Acıbadem University, Istanbul, Turkey; ${ }^{\circ}$ Department of \\ Orthopaedics and Traumatology, Samsun Training and Research Hospital, Samsun, Turkey; ${ }^{d}$ Department of \\ Biochemistry, Faculty of Medicine, Karadeniz Technical University, Faculty of Medicine, Trabzon, Turkey; \\ e Department of Histology and Embryology, Faculty of Medicine, Karadeniz Technical University, Trabzon, Turkey; \\ ${ }^{f}$ Department of Nutrition and Dietetics, Faculty of Health Sciences, Karadeniz Technical University, Trabzon, Turkey
}

\section{Significance of the Study}

- Although several methods are available for accelerating the healing process, fracture healing is a growing health problem. This is the first experimental study that reveals the time-dependent beneficial effects of grayanotoxin and propolis on fracture healing as assessed by radiography and histology.

\section{Keywords}

Grayanotoxin · Mad honey · Propolis · Honey · Fracture healing

\begin{abstract}
Objectives: Delayed healing and non-union of fractures have a significant effect upon patient morbidity. Studies have therefore largely concentrated on accelerating fracture healing. This study was intended to compare the effect of "mad honey" and propolis on fracture healing using radiological and histopathological analysis. Subjects and Methods: Femur fracture was surgically performed on 48 rats, followed by fixation. Animals were then divided into 8 groups: 2 control groups (15- and 30-day) and 6 treatment groups (15- and 30-day normal honey, 15- and 30-day "mad honey," and 15- and 30-day propolis). Rats were sacrificed at the end
\end{abstract}

of these periods, and radiological and histological examinations were performed. Results: Radiological healing in the propolis group after 15-day therapy was statistically better than in the control $(p=0.004)$ and normal honey $(p=0.006)$ groups. After 30-day therapy, healing in the propolis group $(p=0.005)$ and grayanotoxin-containing "mad honey" group ( $p=0.007$ ) were significantly better than in the control group. Histologically, there was a statistically significant difference between the 15-day propolis group and the other groups (control, honey, mad honey: $p=0.003, p=0.003$, and $p=0.002$, respectively). We also found a statistically significant difference when the 30-day propolis group ( $p=0.005)$ and "mad honey" group ( $p=0.007$ ) were compared to the control group. Conclusions: This study shows that grayanotoxin-containing "mad honey" and propolis can accelerate fracture healing.

(c) 2018 The Author(s)

Published by S. Karger AG, Basel

\begin{tabular}{ll}
\hline KARGER & $\begin{array}{l}\text { @ 2018 The Author(s) } \\
\text { Published by S. Karger AG, Basel }\end{array}$ \\
$\begin{array}{l}\text { Openger } \\
\text { E-Mail karger@karger.coms }\end{array}$ \\
www.karger.com/mpp & $\begin{array}{l}\text { This is an Open Access article licensed under the Creative Commons } \\
\text { Attribution-NonCommercial-4.0 International License (CC BY-NC) } \\
\text { (http://www.karger.com/Services/OpenAccessLicense), applicable to } \\
\text { the online version of the article only. Usage and distribution for com- } \\
\text { mercial purposes requires written permission. }\end{array}$
\end{tabular}

Aynur Sahin

Department of Emergency Medicine, Faculty of Medicine

Karadeniz Technical University

TR-61080 Trabzon (Turkey)

E-Mail dr-aynursahin@ hotmail.com 


\section{Introduction}

Setbacks in fracture healing are a growing health problem. These have an adverse psychological impact and also result in workforce and economic losses. Various methods of accelerating fracture healing and permitting a return to daily life as early as possible are currently under investigation [1].

Grayanotoxin (GTX) is found in the flower parts of plant species such as Rhododendron and Kalmia. GTX is present in rhododendron pollens. It is therefore also found in honeys produced from this regional plant. This toxin-containing honey is known locally as "mad honey" [2]. People in this region use locally produced honey as an alternative therapy for wound healing, to treat arthritis, stomach pain, intestinal diseases, and hypertension, and to increase sexual performance $[3,4]$.

Propolis is a complex, adhesive product made by bees from various plant seeds, leaves or stems and plant secretions [1]. The main compounds it contains are flavonoids, which have antioxidant characteristics [5]. Propolis has attracted considerable interest in recent years due to its pharmacological and biological effects. Studies have shown that it possesses anticancer, hepatoprotective, anti-inflammatory, and antioxidant activities $[6,7]$.

Only 1 experimental study has demonstrated positive effects of propolis in fracture healing [8]. However, the effects of GTX in locally produced mad honey, used as an alternative therapy in wound healing, have not been investigated in fracture healing.
The purpose of this study was to investigate and compare the effects of GTX-containing mad honey and propolis on fracture healing, using radiology and histology, in an experimental femur fracture model.

\section{Materials and Methods}

\section{Study Design}

This randomized, controlled, nonblinded experimental study was performed after Institutional Animal Care and Ethics Committee (2011/23) approval was obtained. The study was performed in accordance with guidelines for the housing and care of laboratory animals.

\section{Study Setting and Population}

Forty-eight female Sprague Dawley rats weighing 195-252 g were used. The animals were housed under standard light/dark conditions (12-h light and 12-h dark) at a constant temperature $\left(22^{\circ} \mathrm{C}\right)$ and humidity $(55+5 \%)$ with unrestricted access to standard laboratory animal chow and water.

\section{Study Protocol}

Rats were randomly assigned to 8 groups of 6 members each - 2 control groups (15-day control, 30-day control) and 6 treatment groups (15-day propolis, 30-day propolis, 15-day normal honey, 30-day normal honey, 15-day mad honey, and 30-day mad honey). The same surgical procedure was performed on all groups before treatment. The rats in the treatment groups were treated daily.

\section{Surgical Procedure}

Images of the surgical procedure are shown in Figure 1. Rats were fasted for $4 \mathrm{~h}$ before surgery. For induction of anesthesia, $5 \mathrm{mg} / \mathrm{kg}$ xylazine hydrochloride (Rompun ${ }^{\circledR}$; Bayer Healthcare,

Fig. 1. Surgical procedure.
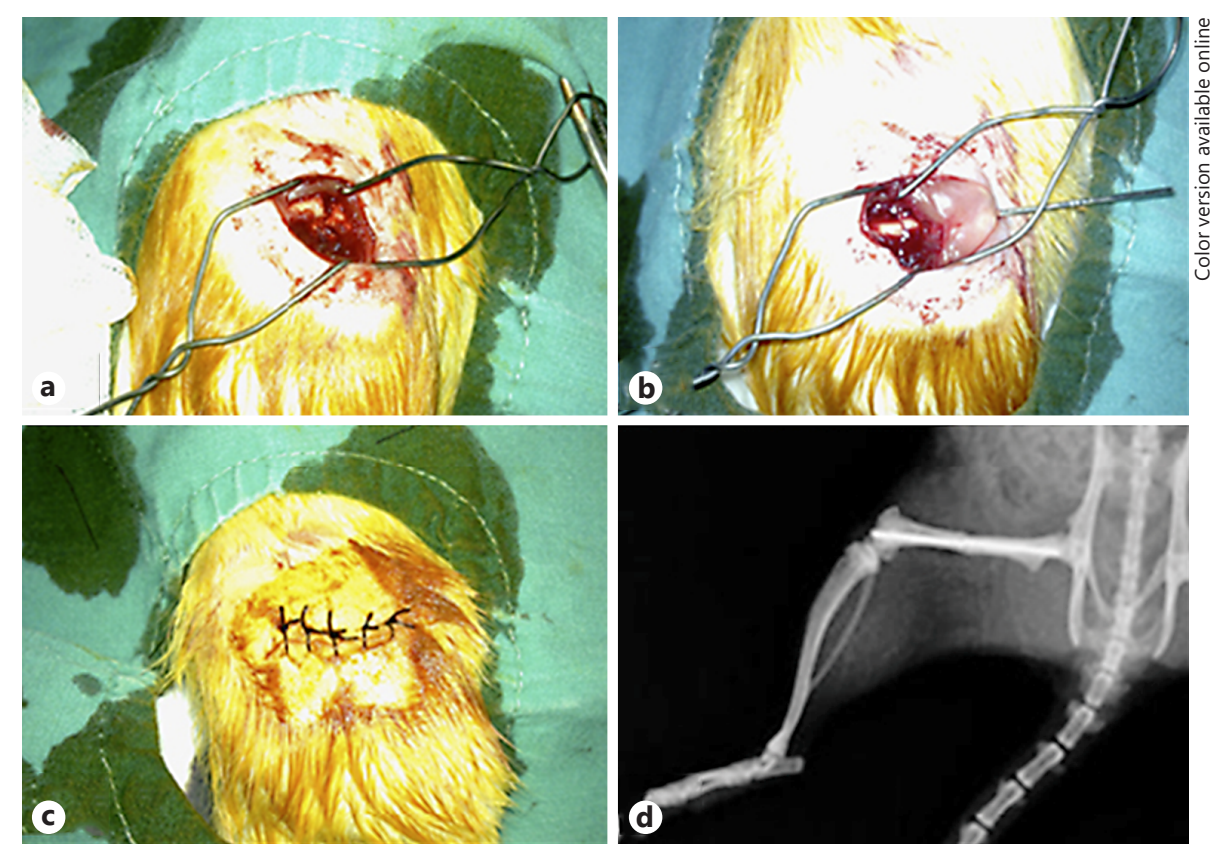
Leverkusen, Germany) and $50 \mathrm{mg} / \mathrm{kg}$ ketamine hydrochloride (Ketalar ${ }^{\circledR}$; Pfizer, Istanbul, Turkey) were administered by the intraperitoneal route. Following appropriate cleaning and covering of the surgical field, the skin of the right thigh was opened approximately $2 \mathrm{~cm}$ from the lateral aspect with a longitudinal incision (Fig. 1a). The femur was accessed. A transverse fracture was then made using a battery-powered drill with $0.8 \mathrm{~mm}$ Kirschner wire (Hipokrat ${ }^{\circledR}$, Izmir, Turkey) (Fig. 1b). The wire was retracted distally, and once the fracture line had been reduced it was moved in a proximal direction in a retrograde manner. The wire was again moved forward with the tip of another wire so that it would be completely buried (Fig. 1c). Once fixation had been established, the accuracy of the fracture line reduction was confirmed using Xray imaging (Fig. 1d). On days 15 and 30, as applicable, rats in the control and treatment groups were sacrificed by cervical dislocation under anesthesia. Right femurs were extracted by disarticulation from the hip and knee. Radiological images were taken, and soft tissue specimens were stored in 10\% formaldehyde for preparation for histological examination.

\section{Treatment Protocols}

Rats received no antibiotic therapy before or after the surgical procedure. No agent was administered for therapeutic purposes in the 15- or 30-day control groups. Each rat in the propolis groups (15and 30 -day) received $200 \mathrm{mg} / \mathrm{kg}$ propolis per day by the orogastric route throughout the study period [8]. The propolis samples used in this study were produced by honeybees (Apis mellifera L.) in Trabzon, Turkey, and were provided by the Trabzon Agricultural Development Cooperative. For stock water $(50,000 \mathrm{mg} / \mathrm{mL})$ preparation, $1 \mathrm{~g}$ of propolis was dissolved in $20 \mathrm{~mL}$ water and then incubated at $60^{\circ} \mathrm{C}$ and $150 \mathrm{rpm}$ in an orbital shaker for $24 \mathrm{~h}$. After incubation, samples were centrifuged at $4000 \mathrm{rpm}$ for $10 \mathrm{~min}$. Supernatants were filtered through filter paper and $0.22 \mathrm{~mm}$ filters [7].

As the mean amount of mad honey consumed for therapeutic purposes by a $70-\mathrm{kg}$ adult is $4-6 \mathrm{~g}$ /day ( 1 teaspoonful), each rat in the mad honey groups (15- and 30-day) received a mean $80 \mathrm{mg} / \mathrm{kg}$ mad honey per day by the orogastric route throughout the study period [1]. Mad honey was obtained from a sample that caused a clinical case of toxicity after consumption; it was confirmed to have originated from a Rhododendron-containing area of the Black Sea Region. The amount of GTX it contained was not measured.

Each rat in the normal honey groups (15- and 30-day) received $80 \mathrm{mg} / \mathrm{kg}$ normal honey per day by the orogastric route. The normal honey (Balparmak ${ }^{\circledR}$ Blossom Honey, Izmir, Turkey) used in the experiments was obtained from supermarkets and then subjected to standard tests in the production facilities.

\section{Radiological Evaluation}

Radiographic images were scored according to the Lane-Sandhu radiological scoring system (Table 1) [9]. Scoring was performed by 2 independent orthopedists blinded to the study groups.

\section{Histopathological Examination}

Tissue specimens were fixed in $10 \%$ neutral formalin, rendered transparent in xylene, and embedded in paraffin blocks. Sections $5 \mu \mathrm{m}$ in thickness were made using a fully automatic microtome (Leica RM 2255, Tokyo, Japan). Compounds were analyzed under light microscopy (Olympus BX51, Japan) by an experienced histologist blind to the groups. Compounds from the groups were photographed using a digital camera (Olympus DP71, Japan) un-
Table 1. The Lane-Sandhu radiographic scoring system

\section{Degree of bone formation}

No new bone formed

The area of new bone accounts for $25 \%$ of the defect area The area of new bone accounts for $50 \%$ of the defect area The area of new bone accounts for $75 \%$ of the defect area The area of new bone accounts for $100 \%$ of the defect area

\section{Degree of union}

Fracture line is fully visible

Fracture line is partially visible

Fracture line is not visible

Degree of medullary cavity remodeling

No sign of remodeling

Recanalization of the medullary cavity

Recanalization of cortical bone

Table 2. The Huo histological scoring system

\begin{tabular}{lc} 
Fracture region findings & Points \\
\hline Fibrous tissue only & 1 \\
Predominantly fibrous tissue & 2 \\
Equal amounts of fibrous and cartilage tissue & 3 \\
Predominantly cartilage tissue with little fibrous tissue & 4 \\
Cartilage tissue only & 5 \\
Predominantly cartilage tissue with little immature bone & 6 \\
Equal amounts of cartilage and immature bone tissue & 7 \\
Predominantly immature bone with little cartilage tissue & 8 \\
Healing with immature bone & 9 \\
Healing with mature bone & 10
\end{tabular}

der a light microscope. The 10-point histological scoring system described by Huo and Troiano [10] was used for histological evaluation of compounds (Table 2).

\section{Statistical Analysis}

Statistical analysis was performed using SPSS (Statistical Package for Social Sciences for Windows v.13.0; SPSS, Chicago, IL, USA) software. During evaluation of radiological and histological scores, the 15- and 30-day groups were separately compared among themselves. Nonparametric tests were used for data analysis. The Kruskal-Wallis test was used for multiple comparisons and the Mann-Whitney $U$ as post hoc test with Bonferroni correction. Values of $p<0.0083$ after correction were regarded as significant.

\section{Results}

\section{Radiological Scoring}

Fifteen- and thirty-day radiological scoring results from the study groups are shown in Tables 3 and 4 . After 
Table 3. Statistical analysis between groups on day 15

\begin{tabular}{|c|c|c|c|c|}
\hline & \multicolumn{4}{|c|}{ Median radiological scores $(95 \% \mathrm{CI})$} \\
\hline & $\begin{array}{l}\text { control } \\
2.5(2-6)\end{array}$ & $\begin{array}{l}\text { normal honey } \\
3.5(2-7)\end{array}$ & $\begin{array}{l}\text { propolis } \\
8.5(7-11)\end{array}$ & $\begin{array}{l}\text { mad honey } \\
5(4-8)\end{array}$ \\
\hline $\begin{array}{l}\text { Control } \\
\text { Normal honey } \\
\text { Propolis } \\
\text { Mad honey }\end{array}$ & & 0.411 & $\begin{array}{l}0.004^{*} \\
0.006^{*}\end{array}$ & $\begin{array}{l}0.061 \\
0.120 \\
0.034\end{array}$ \\
\hline
\end{tabular}

* Mann-Whitney-U test, $p$ values $<0.0083$ ( $p$ value adjusted for Bonferroni correction) are regarded as statistically significant.
Table 4. Statistical analysis between groups on day 30

\begin{tabular}{|c|c|c|c|c|}
\hline & \multicolumn{4}{|c|}{ Median radiological scores $(95 \% \mathrm{CI})$} \\
\hline & $\begin{array}{l}\text { control } \\
9.5(6-12)\end{array}$ & $\begin{array}{l}\text { normal honey } \\
12.5(7-14)\end{array}$ & $\begin{array}{l}\text { propolis } \\
14.5(12-16)\end{array}$ & $\begin{array}{l}\text { mad honey } \\
13(12-16)\end{array}$ \\
\hline $\begin{array}{l}\text { Control } \\
\text { Normal honey } \\
\text { Propolis } \\
\text { Mad honey }\end{array}$ & & 0.126 & $\begin{array}{l}0.005^{*} \\
0.052\end{array}$ & $\begin{array}{l}0.007^{*} \\
0.252 \\
0.458\end{array}$ \\
\hline
\end{tabular}

* Mann-Whitney-U test, $p$ values $<0.0083$ ( $p$ value adjusted for Bonferroni correction) are regarded as statistically significant.
15 days' therapy, animals receiving propolis exhibited significantly higher radiological scores compared to the controls $(p=0.004)$ and subjects receiving normal honey $(p=$ $0.006)$. There was no significant difference between the 15 -day mad honey group and the control group (Table 3 ). Group scores on the 15th day are shown in Figure 2.

After therapy for 30 days, the radiological scores of animals receiving propolis $(p=0.005)$ and mad honey ( $p=0.007)$ were significantly higher than those of the control group (Table 4). No statistically significant differences were observed between the radiological scores of the normal honey group and the control group, or between the propolis and mad honey treatment groups. Group scores on the 30th day are shown in Figure 3.

\section{Histopathological Comparison}

Evaluation of histological grade in subjects receiving therapy for 15 days revealed no histological grade higher than 3 in the control or normal honey groups, and the difference between these two was insignificant. All subjects in the 15-day mad honey group had histological scores of 4 , while all subjects in the 15-day propolis group had histological grade scores of 6 or above (Fig. 4). A significant increase in histological grade was observed in the 15-day propolis group compared to the control $(p=0.003), 15$-day normal honey $(p=0.003)$, and 15 -day mad honey ( $p=$ 0.002 ) groups. No significant increase in histological grade was observed in the 15-day mad honey group compared to the 15-day normal honey or 15-day control groups.

No histological score above 8 was observed in the control or normal honey groups at examination of histological grade after 30 days' therapy. Histology scores of 8 or above were observed in all rats in the 30 -day propolis and mad honey groups. The highest histology grade, i.e., 10, was determined in 1 animal of the propolis group (Fig. 5). Figure 6 shows bone tissue samples from the treatment and control groups on days 15 and 30. A significant increase in histological grade was observed in the 30-day propolis $(p=0.005)$ and 30-day mad honey $(p=0.007)$ groups compared to the control group.

Comparison of the 30-day propolis and 30-day normal honey groups revealed a statistically significant histological improvement in the propolis group $(p=0.008)$. There was no significant difference between the 30 -day mad honey group and the 30 -day propolis or 30 -day normal honey groups. 


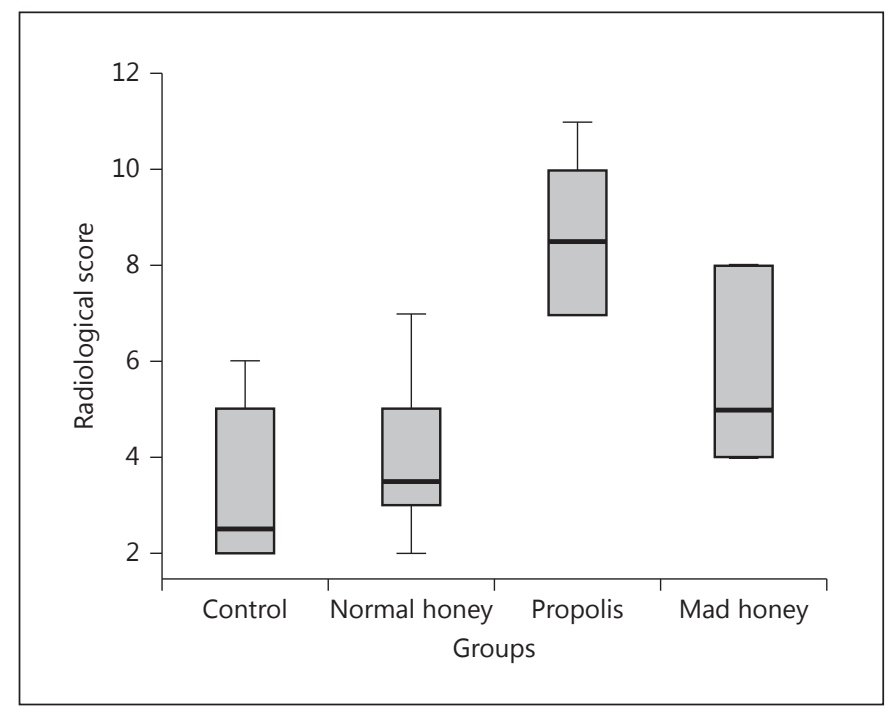

Fig. 2. Specialist scores for the groups on the 15th day of the experiment.

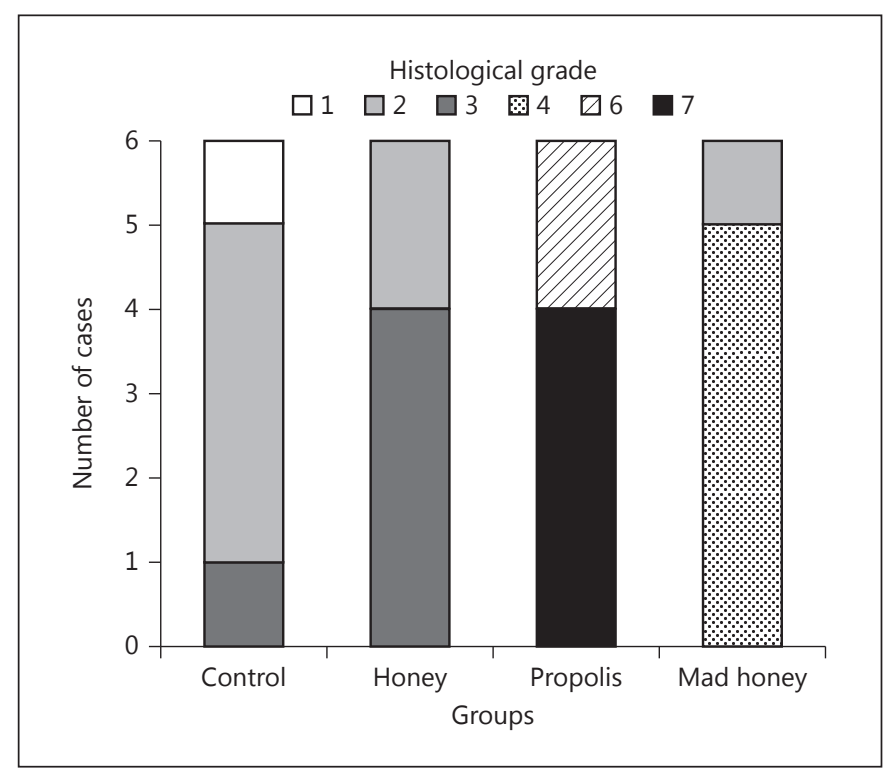

Fig. 4. Histological grades on the 15th day of the experiment.

\section{Discussion}

This experimental study revealed positive effects of propolis and mad honey on fracture healing in an experimental setting, as shown by X-ray and histopathological studies. The study findings may be interpreted as indicating that propolis is more effective than mad honey over both 15- and 30-day treatment periods.

Effects of Mad Honey and Propolis on Fracture Healing

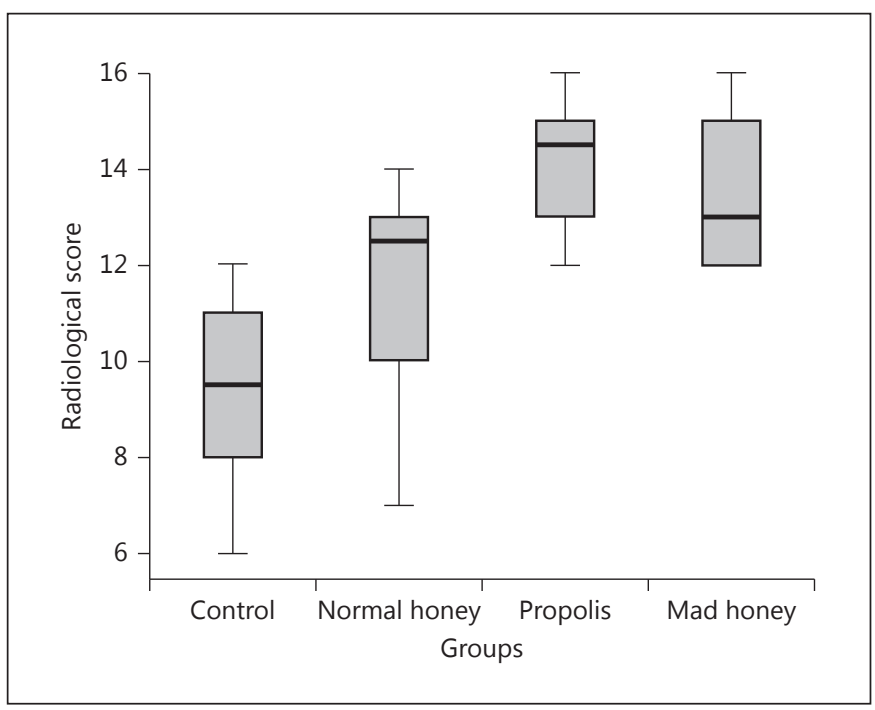

Fig. 3. Specialist scores of the groups on the 30th day of the experiment.

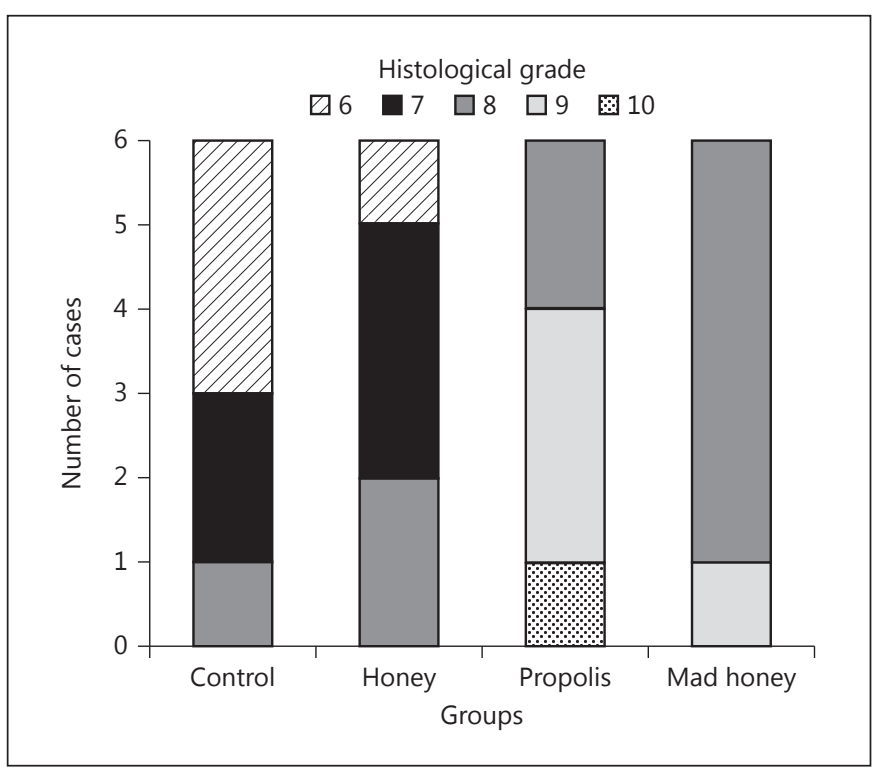

Fig. 5. Histological grades on the 30th day of the experiment.

Evaluation of the radiological and histological scores of the propolis treatment group in our study showed significant healing in both the 15- and 30-day experimental animals compared to the control group. Many cellular and biochemical events such as neurohormonal and neurohumoral mechanisms are involved in fracture healing, and studies have shown that free oxygen radicals have a deleterious impact on healing $[11,12]$. Various drugs and

Med Princ Pract 2018;27:99-106 

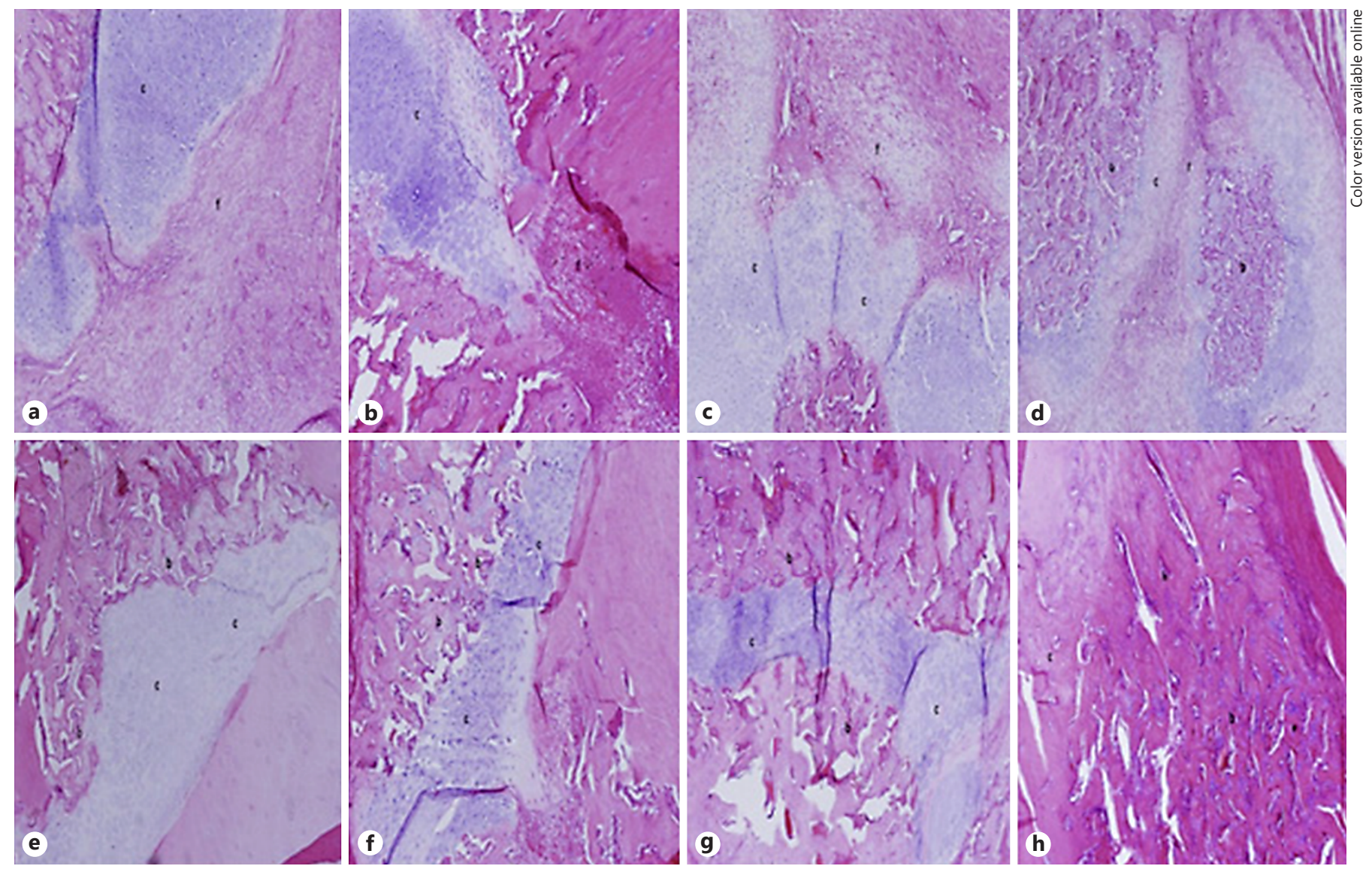

Fig. 6. Histological images at the 15 th day (a-d) and 30th day (e-h). a, e Control. b, f Normal honey. c, $\mathbf{g}$ Mad honey. d, h Propolis. Cartilage tissue (c), fibrous tissue (f), immature bone tissue (b). Hematoxylin eosin. $\times 100$.

factors have been investigated for their ability to accelerate fracture healing. One such is propolis, which possesses antioxidant properties. Propolis consists of 50\% flavonoid- and phenolic acid-based resin and vegetable balsam, $30 \%$ wax, $10 \%$ essential oils, $5 \%$ pollen, and $5 \%$ other organic compounds. Flavonoids in propolis are antioxidants that eradicate free oxygen radicals by donating hydrogen. In addition, flavonoids complexed with iron ions suppress the Fenton reaction that causes hydroxyl radicals [2]. Several studies have demonstrated the antioxidant property of propolis in tissues. In a histomorphometric study, Altan et al. [13] showed that propolis stimulated new bone formation in bone suture separation and increased inflammatory cell numbers and capillary numbers in tissues. Guney et al. [8] observed a positive effect of propolis on fracture healing; they reported that while radiological scores in the 3rd and 6th weeks were better compared to the control group, histological scores were comparable to those of the control group at the 6th week. Our propolis samples were collected in Trabzon in the Northeast of Turkey. Propolis is known to be rich in polyphenolic compounds, such as pinocembrin, isalpinin, pinostropin, naringenin, quercetin, chrysin, pinobanksin, galangin, apigenin, 3,40,7-trimethoxy flavanone, and caffeic acid [14]. The positive effect of propolis described in the literature thus supports the findings of our study.

When the efficacy of the mad honey and control groups was compared in terms of fracture healing, no significant difference was observed as evidenced by radiological and histopathological scores on day 15 of treatment. However, at the end of the 30-day protocol, both scoring results were significantly superior in the mad honey group compared to the control group. As mad honey is used to treat numerous diseases such as diabetes, hypertension, and hyperlipidemia, the mechanisms of action of GTX in these pathologies have been studied [15- 
17]. However, there are no reports on the effects of mad honey on fracture healing.

Several mechanisms may underlie the positive effects observed by us. First, bone metabolism events are affected by the nervous system. Mediators producing this effect include glutamate, catecholamines, leptin, and VIP [18]. Glutamate has been shown to play a significant role in bone-nerve interaction in particular, being associated with other nerve markers in bone cells, and has been reported to play an important role in remodeling after mechanical loading by balancing catabolic and anabolic activities [19]. Kim et al. [20] reported increased GABA and glutamate release after GTX administration. Increased glutamate release after GTX intake may explain the positive effect on bone healing of mad honey. Durdagi et al. [21] showed that GTX-3 inhibits cytosolic carbonic anhydrase 2 in the micromolar range in mammals. Osteoclasts perform bone resorption through hydrogen released by means of carbonic anhydrase. A decrease in the effect of carbonic anhydrase, and thus of osteoclasts, with the administration of GTX may be a possible cause of the positive effect of mad honey on fracture healing. This study showed that GTX-containing mad honey increased vascularity in the fracture region. Yet another reason for the effect of GTX on bone healing may be increased blood flow in association with peripheral vasodilation. Sibel et al. [22] reported that GTX increased antioxidant activity in tissues in their experimental study. The antioxidant property of GTX may therefore explain the positive effect on healing.

Normal honey was included in this study in order to assess its efficacy in terms of fracture healing of other chemical compounds contained in propolis and mad honey. Honey has a complex chemical composition. It contains 25 carbohydrates, free amino acids, vitamins, trace elements, flavonoids, and antioxidant, antimicro- bial, and anti-inflammatory substances [23]. Additionally, substances or toxins specific to the flower flora from which it is obtained may also cause differing effects. Several studies have investigated its use in wound healing and for treating coughs, for boosting the immune system, and for antimicrobial activity $[23,24]$. In our study, the effect on radiological and histopathological scores in the normal honey group in both the 15- and 30-day protocols resulted in no significant improvement in healing compared to the control group. Interestingly, no significant difference was determined between long-term radiological score values in the propolis and mad honey groups and those of the normal honey group.

\section{Limitations}

There are a number of limitations to this study. The amount of GTX contained in the mad honey used in the experimental protocol was not determined using a quantitative method. One of the main limitations of this study is the absence of any investigation of dose response. Blood parameters showing the antioxidant characteristic of GTX and factors increasing blood supply were also not investigated. Biomechanical testing using the contralateral, nonfractured femur as an internal control was also not performed.

\section{Conclusions}

This experimental study reveals a time-dependent beneficial effect of GTX and propolis on fracture healing as evaluated by radiographic and histological assessment. It also shows that GTX and propolis have similar radiological and histological therapeutic effects in bone fracture over a period of 30 days. Further studies are needed to clarify the effects of GTX on fracture healing.

\section{References}

1 Victoria G, Petrisor B, Drew B, et al: Bone stimulation for fracture healing: What's all the fuss? Indian J Orthop 2009;43:117-120.

2 Gunduz A, Turedi S, Russell RM, et al: Clinical review of grayanotoxin/mad honey poisoning past and present. Clin Toxicol 2008; 46:437-442

3 Tatli O, Karaca Y, Turkmen S, et al: The effect of mad honey on testosterone levels of male rats. Bratisl Lek Listy 2016;117:677-680.

4 Gunduz A, Turedi S, Uzun H, et al: Mad honey poisoning. Am J Emerg Med 2006;24: 595-598.
5 Cao XP, Chen YF, Zhang JL, et al: Mechanisms underlying the wound healing potential of propolis based on its in vitro antioxidant activity. Phytomedicine 2017;34:76-84.

6 Wagh VD: Propolis: A wonder bees product and its pharmacological potentials. Adv Pharmacol Sci 2013;2013:308249.

7 Demir S, Aliyazicioglu Y, Turan I, et al: Antiproliferative and proapoptotic activity of Turkish propolis on human lung cancer cell line. Nutr Cancer 2016;68:165-172.
8 Guney A, Karaman I, Oner M, et al: Effects of propolis on fracture healing: an experimental study. Phytother Res 2011;25:1648-1652.

9 Lane JM, Sandhu HS: Current approaches to experimental bone grafting. Orthop Clin North Am 1987;18:213-225.

10 Huo MH, Troiano NW: The influence of ibuprofen on fracture repair: biomechanical, biochemical, histologic, and histomorphometric parameters in rats. J Orthop Res 1991;9:383390.
Effects of Mad Honey and Propolis on Fracture Healing
Med Princ Pract 2018;27:99-106

DOI: $10.1159 / 000487552$ 
11 Khallaf FG, Kehinde EO, Hussein S: Bone healing and hormonal bioassay in patients with long-bone fractures and concomitant head injury. Med Princ Pract 2016;25:336342.

12 Shuid AN, Mohamad S, Muhammad N, et al: Effects of a-tocopherol on the early phase of osteoporotic fracture healing. J Orthop Res 2011;29:1732-1738.

13 Altan BA, Kara IM, Nalcaci R, et al: Systemic propolis stimulates new bone formation at the expanded suture: a histomorphometric study. Angle Orthod 2013;83:286-291.

14 Uzel A, Sorkun K, Oncag O, et al: Chemical compositions and antimicrobial activities of four different Anatolian propolis samples. Microbiol Res 2005;160:189-195.

15 Gunduz A, Kalkan A, Turedi S, et al: Pseudocholinesterase levels are not decreased in grayanotoxin (mad honey) poisoning in most patients. J Emerg Med 2012;43:1008-1013.
16 Gunduz A, Eraydın I, Turkmen S, et al: Analgesic effects of mad honey (grayanotoxin) in mice models of acute pain and painful diabetic neuropathy. Hum Exp Toxicol 2014;33: 130-135.

17 Oztasan N, Altınkaynak K, Akcay F, et al: Effects of mad honey on blood glucose and lipid levels in rats with streptozocin-induced diabetes. Turk J Vet Anim Sci 2005;29:10931096.

18 Jones KB, Mollano AV, Morcuende JA, et al: Bone and brain: a review of neural, hormonal and musculoskeletal connections. Iowa Orthop J 2004;24:123-132.

19 Skerry TM, Taylor AF: Glutamate signalling in bone. Curr Pharm Des 2001;7:737-750.
20 Kim SE, Shin MC, Akaike N, et al: Presynaptic effects of grayanotoxin on excitory and inhibitory nerve terminals in rat ventromedial hypothalamic neurons. Neurotoxicology 2010; 31:230-238.

21 Durdagi S, Scozzafava G, Vullo D, et al: Inhibition of mammalian carbonic anhydrases IXIV with grayanotoxin III: solution and in silico studies. J Enzyme Inhib Med Chem 2014;29:469-475.

22 Sibel S, Enis YM, Hüseyin S, et al: Analysis of grayanatoxin in Rhododendron honey and effect on antioxidant parameters in rats. J Ethnopharmacol 2014;156:155-161.

23 Oduwole O, Meremikwu MM, Oyo-Ita A, et al: Honey for acute cough in children. Cochrane Database Syst Rev 2012:CD 007094.

24 Zbuchea A: Up-to-date use of honey for burns treatment. Ann Burns Fire Disasters 2014;27: 22-30. 